A N N A L E S

UNIVERSITATIS MARIAE CURIE-SKŁODOWSKA

LUBLIN - POLONIA

VOL. LXXII

SECTIO F

2017

Maria Curie-Skłodowska-Universität, Lublin

RYSZARD SZCZYGIEL

urbs_nova@o2.pl

\title{
Die Lokation Lublins nach Magdeburger Recht und der Weg zur Blüte der Stadt im 14. Jahrhundert
}

Lokacja Lublina na prawie magdeburskim i jego droga ku świetności w XIV w.

\section{ZUSAMMENFASSUNG}

$\mathrm{Zu}$ Beginn des 14. Jahrhunderts erreichte die Bewegung der Lokation von Dörfern und Städten nach deutschem Recht auch das Lubliner Land. Die erste Stadt auf diesem Territorium, die nach dem Lokationsmodell modernisiert wurde, war Lublin. Die Rechtsgrundlage dieser Investition, die von Maciej (Matthias) durchgeführt wurde, dem Landhauptmann von Krakau und Sandomir und zugleich Erbvogt in der Stadt Opatowiec (Sandomirer Land), bildete das Lokationsprivileg des Herzogs Władysław Łokietek (Ellenlang), das am 15. August 1317 „,bei Krakau“ ausgestellt wurde.

Bis zu dieser Zeit war Lublin ein Siedlungsensemble, das aus mehreren, auf Hügeln gelegenen Siedlungsbereichen bestand: auf dem Schlosshügel (die Burg), dem Altstadthügel (eine protostädtische Siedlung), Czwartek und Żmigród. Die Stadtinvestition wurde auf dem Altstadthügel mit einer Fläche von 7 Hektar in schachbrettartiger Ordnung geplant und durchgeführt. Es entstand auch eine Stadtgemeinde, die sich nach Magdeburger Recht regieren sollte; an ihrer Spitze stand der Erbvogt Maciej. Die Bewohner der Stadt erhielten zahlreiche Privilegien, u.a. eine zwanzigjährige Freistellung von Steuern für den Herzog sowie die Befreiung von Zollgebühren auf dem Territorium seines Staates.

Der Lokationsprozess dauerte auch unter der Herrschaft von König Kasimir dem Großen fort. Damals entstanden zahlreiche gemauerte Gebäude, und es wurden auch Wehrmauern errichtet. Lublin war damals ein grenznahes Etappenziel für den Großhandel und eine Basis für Kriegszüge des Königs gegen die Rus'. Die Rolle der Stadt wuchs rapide nach der Polnisch-Litauischen Union in den Jahren 1385-1386, als sie sich im Zentrum der Monarchie von Władysław Jagiełło zwischen Polen, Litauen und der Rus' befand und als Zentrum für den Handelsaustausch und für Hoftage der politischen Eliten beider Staaten - des polnischen und des litauischen - fungierte. Im Verlauf des 15. Jahrhunderts stieg Lublin in die Liga der wichtigsten Städte der Jagiellonenmonarchie auf.

Schlüsselwörter: Lublin; Lokation; Stadtgemeinde; Magdeburger Recht 
Wie die europäische Historiographie einträchtig annimmt, waren die Lokationsstädte Stätten wirtschaftlich-sozialer Entwicklung und zivilisatorischen Fortschritts. Sie förderten die Verbreitung des Wissens und der Technik, auf ihrem Gebiet entstanden Verhaltensmuster für die alltägliche Arbeit der Bürger, allgemeine Verhaltensnormen und Kulturmodelle. Der französische Historiker Fernand Braudel verglich die Rolle der Städte im Ansiedlungsnetz mit der Rolle vor Transformatoren im elektrischen Netz und erblickte in ihnen vor allem Orte, die die Aufnahme zwischenmenschlicher Kontakte erleichterten ${ }^{1}$. Sie waren also eine spezifische Form der Bewirtschaftung des Raumes und der Organisation der sie bewohnenden Gemeinschaft und zeichneten sich im Ansiedlungsnetz durch die ausgeübten Funktionen aus. Für die polnischen Gebiete bedeutete das eine Modernisierung der Wirtschaft und des gesellschaftlichen Lebens in Anlehnung an den Anstieg der Rolle des Geldes und die Intensivierung des Handelsaustausches ${ }^{2}$.

Das Organisationsprogramm des Umbaus von Städten und Dörfern wurde im 13. Jahrhundert aus Westeuropa auf die polnischen Gebiete übertragen. Der Umbau war Teil eines großen Prozesses mit europäischer Reichweite ${ }^{3}$. Er erfolgte nach den Prinzipien, die die deutsche Kolonisation mit sich brachte. In der polnischen Literatur bezeichnet man ihn häufig als Lokationsumbruch ${ }^{4}$. Dieser Umbau

1 F. Braudel, Civilisation matérielle, économie et capitalisme, XVe-XVIIIe siècle, Vol. I: Les structures du quotidien: le possible et l'impossible, Paris 1979, S. 421.

2 M. Bogucka, H. Samsonowicz, Dzieje miast i mieszczaństwa w Polsce przedrozbiorowej, Wrocław 1986, S. 45-53; S. Gawlas, Polska Kazimierza Wielkiego a inne monarchie Europy Środkowej - możliwości i granice modernizacji władzy, [in:] Modernizacja struktur władzy $w$ warunkach opóźnienia. Europa Środkowa i Wschodnia na przełomie średniowiecza i czasów wczesnonowożytnych, red. M. Dygo u.a., Warszawa 1999, S. 14-17; J. Kurtyka, Odrodzone Królestwo. Monarchia Władysława Łokietka i Kazimierza Wielkiego w świetle nowych badań, Kraków 2001, S. 189-197; H. Samsonowicz, Miejsce Polski w Europie, Warszawa 1996, S. 5397; Gawlas S., O ksztatt zjednoczonego królestwa. Niemieckie władztwo terytorialne a geneza spoteczno-ustrojowej odrębności Polski, Warszawa 2000, S. 78-87.

3 E. Ennen, Die europäische Stadt des Mittelalters, 3. Aufl., Götingen 1979, S. 100ff.; A.E.J. Morris, A History of Urban Form. Belfore the Industrial Revolutions, 3. Aufl., New York 1994, S. 119ff.; J. Heers, La ville au Moyen Âge en Occident. Paysages, pouvoirs et contiflicts, Paris 1990, S. 96ff.; A. Wędzki, Początki reformy miejskiej w Europie Środkowej do połowy XIII w., Warszawa-Poznań 1974; T. Rosłanowski, Z zagadnień lokacji miejskich w Europie Zachodniej $i$ Środkowo-Wschodniej w średniowieczu, [in:] Studia nad etnogeneza Stowian i kultura Europy wczesnośredniowiecznej, red. G. Labuda, S. Tabaczyński, t. 2, Wrocław 1988, S. 119-123; R. Bartlett, The Making of Europe. Conquest, Colonization and Cultural Change 950-1350, London 1994, S. 256ff.; S. Gawlas, Przełom lokacyjny w dziejach miast środkowoeuropejskich, [in:] Civitas Posnaniensis. Studia z dziejów średniowiecznego Poznania, red. Z. Kurnatowska, T. Jurek, Poznań 2005, S. 138-139 (dort weitere Literaturhinweise).

4 B. Zientara, Przełom $w$ rozwoju miast środkowoeuropejskich $w$ pierwszej połowie XIII w., „Przegląd Historyczny” 1976, t. 67, S. 219-223; idem, Przemiany społeczno-gospodarcze i przestrzenne miast $w$ dobie lokacji, [in:] Miasta doby feudalnej w Europie Środkowo-Wschodniej. Przemiany społeczne a układy przestrzenne, red. A. Gieysztor, T. Rosłanowski, Warszawa 1976, S. $73-$ 80; M. Bogucka, H. Samsonowicz, op. cit., S. 45ff.; S. Gawlas, Przełom lokacyjny..., S. 133-162. 
hing mit breiten wirtschaftlichen, gesellschaftlichen und rechtlich-systemischen Umwandlungen zusammen, die Dörfer und Städte umfassten. Im Ergebnis kam es zur Rationalisierung und zum Anstieg der landwirtschaftlichen Produktion, zur Entwicklung der Marktwirtschaft, zur Annahme neuer Regeln des Funktionierens feudaler Güter und zur neuen Organisation kollektiven Lebens. Gleichzeitig schlossen sich die polnischen Gebiete dem internationalen Handelsaustausch an und begannen am europäischen Handel teilzunehmen ${ }^{5}$.

Die Organisation der Städte erfolgte also unter Nutzung von westeuropäischen Mustern, von Grundsätzen der Raumplanung, die sich auf den Gebieten zwischen Elbe und der Oder bewährt haben, bei rechtlicher Berücksichtigung der Bürger, die persönliche Freiheit erlangten ${ }^{6}$. Das erfolgte durch die Verleihung der sog. „deutschen“ Stadtrechte?.

Neben einem mit dem Pachtzins verbundenen System von Pflichten gab das deutsche Recht den Bürgern die Möglichkeit, sich einer nichtlandwirtschaftlichen Tätigkeit (Handel, Handwerk und Dienstleistungen) zu widmen ${ }^{8}$. Den Bewohnern der organisierten Städte verlieh man Vorrechte, die die Organisation des wirtschaftlichen Lebens, die innere Ordnung, die Schlichtung von Streitigkeiten und die Bildung von Berufskorporationen betrafen. Die Verleihung des deutschen Rechts war auch eine Prämisse für die Ausbildung der städtischen Selbstverwaltung, was in den nachfolgenden Perioden der Entwicklung der städtischen Zentren erfolgte und vom Verhältnis zwischen der Stadt und ihrem Besitzer abhängig war9 .

In der polnischen Geschichtsschreibung hat sich die Ansicht verfestigt, dass die Übernahme von Kolonisationsmustern bei der Organisation von Städten keine direkte Nachahmung, sondern eine allmähliche Anwendung der Elemente deutschen Rechts ,je nach ökonomischen Bedürfnissen und nach der aktuellen politischen Situation“"war, wie es Benedykt Zientara vor 40 Jahren formulierte ${ }^{10}$. Bei Lokationsvorhaben wurden Änderungen und Verbesserungen

5 A. Mączak, H. Samsonowicz, Z zagadnień genezy rynku europejskiego: strefa baltycka, „Przegląd Historyczny” 1964, t. 55, S. 198-220; M. Małowist, Wschód a Zachód Europy w XIIIXVI wieku, Warszawa 1975; M. Bogucka, H. Samsonowicz, op. cit., S. 45-58; S. Gawlas, Polska Kazimierza Wielkiego..., S. 14-17; idem, O ksztalt zjednoczonego królestwa ..., S. 78-94.

6 Das Modell der Lokationsstadt bespricht S. Gawlas, O ksztalt zjednoczonego królestwa..., S. 26-37, 89-90; siehe auch M. Bogucka, H. Samsonowicz, op. cit., S. 45-62.

7 Ibidem, S. 49-60; K. Kamińska, Lokacje miast na prawie magdeburskim na ziemiach polskich do 1370 r., Toruń 1990, S. 9-12.

8 H. Samsonowicz, Cechy rzemieślnicze w średniowiecznej Polsce. Mity i rzeczywistość, „Przegląd Historyczny” 1984, t. 75, S. 351-366; idem, Struktura zawodowa mieszczaństwa w dawnej Polsce, [in:] Historia i archiwistyka. Ksiegga pamiątkowa ku czci profesora Andrzeja Tomczaka, red. J. Dygdała, B. Woszczyński, Torun 1992, S. 43-51; M. Bogucka, H. Samsonowicz, op. cit., S. 129-164.

9 Ibidem, S. 55-62.

${ }^{10}$ B. Zientara, Przemiany..., S. 74. 
eingeführt. Die Entwicklung hatte ansonsten verschiedene Intensität in den einzelnen Regionen ${ }^{11}$ und umfasste sowohl räumliche Umwandlungen der bereits bestehenden Siedlungen, deren Einwohnern neue Vorrechte und Privilegien verliehen wurden, als auch die Gründung neuer Siedlungen, in denen das volle Lokationsprogramm zur Anwendung gelangte ${ }^{12}$.

Władysław I. Ellenlang, Herzog von Krakau und Sandomierz, Erbe des Königreichs Polen, stellte am Montag, dem 15. August 1317, bei Krakau (apud Cracoviam) eine Urkunde aus, in der er seinem Statthalter Maciej, der auch das Amt des Vogtes in Opatowiec (eine Stadt im Land Sandomierz) bekleidete, die Lokation der Stadt Lublin nach Magdeburger Recht befah $1^{13}$. Inhalt dieser Urkunde war das Programm einer Modernisierung der Stadt, dank dem Lublin ein Teil der großen Familie europäischer Städte wurde, die nach dem Modell des städtischen Rechts organisiert waren.

Die Lokationsbewegung begann in Schlesien und wurde ein Muster für andere Landesteile ${ }^{14}$. Aus den Beiträgen von Feliks Kiryk resultiert, dass sie im 13. Jahrhundert den westlichen Teil Kleinpolens erfasste, hauptsächlich die Gebiete rund um Krakau ${ }^{15}$. Jerzy Wyrozumski schrieb wiederum, dass auf den Gebieten östlich vom Dunajec und von der mittleren Weichsel im 13. Jh. „,keine einzige städtische Gemeinde entstand. Der ganze [...] Prozess begann hier erst im 14. Jh." ${ }^{\text {"16. }}$. Diese Bemerkung bezieht sich auf das Lubliner Land, also die Gebiete zwischen Weichsel und Wieprz, dem Unterlauf des San und dem Einzugsgebiet der Tyśmienica. Lublin war das erste Zentrum, das auf diesem Gebiet nach dem Programm einer Lokationsstadt umgebaut wurde. Die Grundlage dafür war die

${ }^{11}$ H. Samsonowicz, Tendencje rozwoju sieci miejskiej w Polsce późnośredniowiecznej, „Kwartalnik Historii Kultury Materialnej” 1980, t. 28, S. 341-345; J. Wyrozumski, Rozwój sieci miejskiej w Małopolsce $w$ średniowieczu $i$ u progu czasów nowożytnych, „Kwartalnik Historii Kultury Materialnej” 1980, t. 28, S. 363-371; J. Wiesiołowski, Sieć miejska Wielkopolski w XIIIXVI wieku. Przestrzeń i społeczeństwo, „Kwartalnik Historii Kultury Materialnej” 1980, t. 28, S. 386-389; M. Młynarska-Kaletynowa, Rozwój sieci miejskiej na Śląsku na przełomie XII/XIII $i$ w XIII w., „Kwartalnik Historii Kultury Materialnej” 1980, t. 28, S. 349-360; S. Gawlas, O ksztalt zjednoczonego królestwa..., S. 32-37, 88-92; idem, Przełom lokacyjny..., S. 135-139, 151-153.

12 B. Zientara, Przemiany ..., S. 78-79; S. Gawlas, Przełom lokacyjny ..., S. 135.

${ }_{13}$ Kodeks dyplomatyczny Małopolski, red. F. Piekosiński, t. 2, Kraków 1886, Nr. 569 (ferner $-\mathrm{KdM})$.

${ }_{14}$ M. Młynarska-Kaletynowa, op. cit., S. 349-353; H. Samsonowicz, Tendencje rozwoju..., S. 344-347; M. Bogucka, H. Samsonowicz, op. cit., S. 77-86.

${ }^{15}$ F. Kiryk, Rozwój urbanizacji Matopolski XIII-XVI wieku. Województwo krakowskie (powiaty południowe), Kraków 1985; idem, Urbanizacja Małopolski. Województwo sandomierskie XIII-XVI wiek, Kielce 1994; idem, Lokacje miejskie nieudane, translokacje miast i miasta zanikte w Matopolsce do połowy XVII stulecia, „Kwartalnik Historii Kultury Materialnej” 1990, t. 28, S. 373-383.

${ }_{16}$ J. Wyrozumski, Czy późnośredniowieczny kryzys feudalizmu dotknąt Polskę, [in:] Homines et societas. Czasy Piastów i Jagiellonów. Studia historyczne ofiarowane A. Gąsiorowskiemu w 65. rocznicę urodzin, red. T. Jasiński, T. Jurek, J.M. Piskorski, Poznań 1997, S. 107. 
Urkunde von Władysław Ellenlang vom 15. August 1317, die als Lokationsprivileg der Stadt anzuerkennen ist.

In der Historiographie Lublins erschienen im 20. Jh. Zweifel darüber, ob die Urkunde von 1317 sein erstes Lokationsprivileg war. Darüber schrieb Zofia Froehlichowa, später Jan Riabinin ${ }^{17}$. Er berief sich dabei auf die Erklärung der Ratsherren vor den Revisoren der königlichen Güter in den Jahren 1614 und 1661, in der sie bekundeten, dass ein noch vor 1317 ausgestelltes Privileg bei einem tatarischen Überfall verloren gegangen sei. In seinem Beitrag Data lokacji Lublina (Das Datum der Lokation von Lublin, 1961) trat Wiesław Müller mit der These auf, dass die Lokation von Lublin nach deutschem Recht in den Jahren 1253-1259 erfolgte, als man der Stadt ein Lokationsprivileg verlieh. Er berief sich ebenfalls auf die Eintragungen der Revisionen aus den Jahren 1614, 1616 und 1661 über den Verlust des Privilegs in der Zeit des Überfalls der Tataren. Viel Aufmerksamkeit widmete er ansonsten dem Inhalt des Privilegs von 1317, das nach seiner Ansicht kein Lokationsprivileg, sondern eine Urkunde der Verleihung des Amtes eines Vogtes sei - die Lokation sei hingegen früher erfolgt. Bei der Analyse des Inhalts hob er hervor, dass die Lubliner Bürger bei der Gewährung der Freijahre von Zinsen befreit wurden, die sie vermutlich bereits vor 1317 zahlen mussten. Er erinnerte allerdings auch daran, dass ein solcher Zins „bei uns auch in Siedlungen bekannt war, die nach dem sog. polnischen Recht gegründet wurden“, und fügte hinzu, dass dieser Zins nur den benutzten Boden betraf und dass es in dieser Urkunde keine Informationen über die Höhe der Abgaben für die Benutzung von Plätzen und die Betreibung von Läden und Krambuden gab, da sie möglicherweise bereits im vorigen Privileg festgelegt wurde ${ }^{18}$. Es sei hier daran erinnert, dass eine der Hauptbestimmungen, die nach der Lokation nach deutschem Recht in den Städten zu gelten begann, die Festlegung des Geldzinses war. Die Befreiung davon bezog sich in Lublin auf die gewährten Freijahre nach der Lokation.

Dieses Problem besprach 1968 sehr eingehend der verdienstvollste Forscher des mittelalterlichen Lublin Kazimierz Myśliński, der der Hypothese von W. Müller kritisch begegnete und feststellte: „Die Verleihung des Amtes des Vogtes von Lublin durch Władysław Ellenlang im Jahr 1317 ist also ein rechtlicher Ausdruck, eine Form des Lokationsprivilegs, und das Privileg von 1317 ist die erste Lokationsurkunde der Stadt" ${ }^{\star 19}$. Diesem Urteil kann man ohne Bedenken

17 Z. Froehlichowa, Z dziejów organizacji władz miejskich Lublina do końca XVII w., „Pamiętnik Lubelski” 1930, t. 1, S. 76; J. Riabinin, Materiaty do historii miasta Lublina 1317-1792, Lublin 1938, S. VII.

18 W. Müller, Data lokacji Lublina, „,Roczniki Humanistyczne” 1960, t. 9 , z. 4 (Druck - 1961), S. 101-107.

${ }^{19}$ K. Myśliński, Najstarszy Lublin - proces tworzenia się średniowiecznego miasta, „Rocznik Lubelski” 1966, t. 9 (Druck - 1968), S. 180-181. 
zustimmen auch vor dem Hintergrund der Diskussion über die Glaubwürdigkeit der Lokationsprivilegien, die nach dem Erscheinen des Buches Przywileje prawa niemieckiego miast $i$ wsi malopolskich XIV i XV w. (Privilegien des deutschen Rechts von kleinpolnischen Städten und Dörfern des 14. und 15. Jh.) von Stanisław Kuraś 1971 geführt wurde ${ }^{20}$.

Alle beiden Verfasser übersahen ansonsten die Eintragung im 1959 herausgegebenen Buch Lustracja województwa lubelskiego 1565 (Die Revision der Wojewodschaft Lublin 1565). Dort lesen wir: „Die Ratsherren haben dem revisorischen Amt das Privileg Regis Wladislai de data 1317 vorgelegt, das die Lokation der Stadt und Einsetzung eines Vogtes erlaubte ${ }^{\text {"21 }}$. Auch in den handschriftlichen Texten der Revisionen aus den Jahren 1570, 1602 und 1614 beginnt die Beschreibung der Einkünfte der Stadt mit der Erinnerung an die Urkunde von 1317, wonach die Feststellung erfolgt, dass dieses Dokument die Grundlage „der Lokation der Stadt" ist. Es erwähnen sie auch die Revisionen aus den Jahren 1616-1617 und 1661,wo aber von der Lokation nicht die Rede ist. In den Texten der Revisionen seit 1602, bei der Beschreibung der Einkünfte der Starostei Lublin aus der Hufensteuer, erscheinen Mitteilungen, dass die Ratsherren auf die Frage nach dem Lokationsprivileg über den Verlust dieses Privilegs, das älter als die Urkunde von 1317 war, in der Zeit des Überfalls der Tataren informierten. Eben auf diesen Ausschnitt aus der Revision beriefen sich J. Riabinin und W. Müller. Dies war also die Antwort der Lubliner Ratsherren auf die Frage der Revisoren nach dem Lokationsprivileg, die wiederum erwarteten, dass man ihnen eine Urkunde mit einem Inhalt vorlegte, wie er damals in der königlichen Kanzlei üblich war. Es ist noch hinzuzufügen, dass die Urkunde von Herzog Władysław Ellenlang von den Behörden der Stadt wiederholt mehreren polnischen Königen zur Bestätigung vorgelegt wurde. Zunächst war dies König Sigismund der Alte. Man erinnerte an sie in anderen städtischen Privilegien, und trug an erster Stelle in die Kopierbücher der städtischen Gemeinde ein. In Anbetracht dessen kann man kaum behaupten, dass es in Lublin die Tradition eines älteren Lokationsprivilegs als jenes von $1317 \mathrm{gab}^{22}$.

Als Józef Szymański 1967 den Text und die Übertragung des Privilegs von 1317 publizierte, nannte er es die erste bekannte Lokationsurkunde Lublins. Dabei ging er auf die These ein, dass es möglicherweise eine frühere Urkunde gab. Wichtig war auch die Betonung, dass die Urkunde des Verkaufs des Vogtamtes

${ }^{20}$ S. Kuraś, Przywileje prawa niemieckiego miast $i$ wsi małopolskich $X I V-X V$ wieku, Wrocław 1971.

${ }^{21}$ Lustracja województwa lubelskiego 1565, red. A. Wyczański, Wrocław 1959, S. 3.

${ }^{22}$ Siehe dazu: R. Szczygieł, Kiedy Lublin otrzymat pierwszy przywilej lokacyjny na prawie niemieckim?, [in:] Cum gratia et amicitia. Studia z dziejów osadnictwa dedykowane Pani Profesor Marcie Młynarskiej-Kaletynowej z okazji 65-lecia działalności naukowej, red. D. Adamska, K. Chrzan, A. Pankiewicz, Wrocław 2017, S. 281-289. 
von 1342 das Privileg von 1317 erwähnt und die Rechte der Erbvögte nennt, die dort beschrieben sind ${ }^{23}$.

Auch wenn K. Myśliński der Hypothese von W. Müller kritisch gegenüberstand, fand sie ihre Fortsetzer. Die Herausgeber der Quellensammlung Lublin w dokumencie (Lublin im Dokument), in der die Übersetzung der Urkunde von 1317 enthalten ist, stellten fest, dass dies das erste bekannte Dokument über die Verleihung der deutschen Stadtrechte ist, und fügten hinzu: „Die Urkunde von 1317 kann man nicht als eine Lokation anerkennen. Der Vogt galt nicht als Lokator und Lublin als Stadt (civitas) gab es bereits vor dem Jahr 1317“. Sie beriefen sich dabei u.a. auf das Urteil von Z. Froehlichowa und W. Müller ${ }^{24}$.

Der bekannte Kunsthistoriker Stanisław Michalczuk publizierte 1970 seine Studie über den Ursprung des städtebaulichen Systems von Lublin, in der er feststellte, dass es um die Mitte des 13. Jh. zu einer deutlichen Entwicklung eines befestigten städtischen Zentrums kam. Die protourbane Siedlung befand sich auf dem Gelände zwischen dem späteren Städtischen Tor und dem Bogen der Rybnaund der Złota-Straße $\mathrm{e}^{25}$. Bei ihren später erfolgten Untersuchungen berücksichtigten die Archäologen Stanisława Hoczyk-Siwkowa, Irena Kutyłowska, Andrzej Hunicz und Andrzej Rozwałka sowohl die Hypothese von W. Müller als auch die Analyse des städtebaulichen Systems von S. Michalczuk ${ }^{26}$. Eine frühere Lokation hält Jarosław Marczewski in seinem 2002 publizierten Beitrag für möglich, auch wenn er einräumt, dass erst die Urkunde von 1317 die rechtlichen Grundlagen änderte und Lublin den Status einer Stadt nach dem Magdeburger Recht verlieh $^{27}$. In dem 2006 erschienenen Band Lublin wczesnośredniowieczny (Das frühmittelalterliche Lublin) von A. Rozwałka, R. Niedźwiadek und M. Stasiak lesen wir: „Der Verleihungsurkunde von Władysław Ellenlang von 1317 gingen möglicherweise herzogliche Aktivitäten voraus, deren Ziel die Etablierung Lublins als eines nach dem deutschen Recht organisierten Zentrums war. Da die Quellen fehlen, kann man sich auf die Zeit der Markierung des Gebiets der ursprünglichen Lokationsstadt nicht präzise beziehen. Vielleicht erfolgte das im Zusammenhang mit dem Wiederaufbau Kleinpolens durch Bolesław den Schamhaften nach den Überfällen der Mongolen um die Mitte des 13. Jahrhunderts“"28. Die Verfasser

${ }^{23}$ J. Szymański, Dokument lokacyjny Władysława Łokietka dla Lublina z 1317 roku, [in:] Lublin 1317-1967, red. H. Zins, Lublin 1967, S. 272.

${ }^{24}$ Lublin $w$ dokumencie 1317-1967, red. F. Cieślak, H. Gawarecki, M. Stankowa, Lublin 1976, S. 45.

${ }^{25}$ S. Michalczuk, O poczatkach Lublina, czyli geneza ukladu urbanistycznego Starego Miasta, „Biuletyn Historii Sztuki” 1970, nr 2, S. 206-209.

26 Über diese Forschungen schrieben A. Rozwałka, R. Niedźwiadek, M. Stasiak, Lublin wczesnośredniowieczny, Warszawa 2006, S. 21-33.

27 J.R. Marczewski, Duszpasterska działalność kościoła w średniowiecznym Lublinie, Lublin 2002, S. 38.

28 A. Rozwałka, R. Niedźwiadek, M. Stasiak, op. cit., S. 133-134. 
sprachen sich also für die Datierung der ersten Lokationsinitiative aus, wie sie W. Müller vorgeschlagen hatte. Anerkennend ist hervorzuheben dass sie die These über die Lokation im 13. Jahrhundert nicht wie eine Gewissheit behandeln.

Ich muss zugeben, dass auch ich seinerzeit durch die Suggestion beeinflusst war, dass der Umbau der protourbanen Siedlung in Lublin möglicherweise im 13. Jh. erfolgte. In den Beiträgen aus den Jahren 2008 und 2009 mutmaßte ich, dass gewisse Elemente des Lokationsprogramms (Gestaltungsplan des Altstädtischen Hügels, Pflichten in Form von Geldzins, Bau einer gemauerten Pfarrkirche) in der zweiten Jahrhunderthälfte realisiert wurden; die auf das Privileg von 1317 gestützte Modernisierung nannte ich eine „,volle Stadtlokation“29. Heute aber, nach einer erneuten, vollständigen Untersuchung der Quellen und der Literatur beschloss ich, diesen Standpunkt zu revidieren und dem Privileg von Herzog Władysław Ellenlang erneut einen gebührenden Platz im Lokationsprozess von Lublin, dessen Programm der Inhalt dieser Urkunde bildete, zuzuerkennen. Ihre Struktur, die von dem in der Literatur üblichen Archetyp abweicht, hing davon ab, dass man in der herzoglichen Kanzlei bei der Niederschrift des Dokuments eben ein solches Formular verwendete ${ }^{30}$.

In der zweiten Hälfte des 13. Jh. war Lublin Zentrum einer Landschaft, die im Sandomirer Land zunehmend an Selbstständigkeit gewann. Der Sitz des Kastellans, der im Lubliner Land die administrative Macht ausübte, befand sich auf dem Burghügel. Vor der Burg, auf dem Altstädtischen Hügel, gab es eine dem Kastellan unterstellte Siedlung, deren Einwohner ihre Dienstleistungen für die Burg anboten. Daneben, im nordöstlichen Teil des Hügels, befand sich die Siedlung des Lubliner Archidiakons. Es stand hier vermutlich die St. Michaelis-Kirche aus Holz, die wohl die Hauptkirche des Archidiakons war. Wo die Grenzen dieser Siedlung verliefen, kann man heute nicht mehr bestimmen. Nur allgemein lässt sich feststellen, dass zu ihr das Gelände vor dem späteren Städtischen Tor bis hin zum südlichen Rand des Hügels gehörte. Die westliche Grenze konnte die Grodzka-Straße bilden. Auf diesem Gebiet errichtete man die ersten Gebäude und das Gotteshaus des in dieser Periode gestifteten Dominikanerklosters. Die Einwohner der beiden Siedlungen befassten sich mit dem Handwerk, dem Handel und der Landwirtschaft. An der Grodzka-Straße, in der Nähe der Pfarrkirche, befand sich ein Markt. Die westliche Seite der Straße war nämlich in dieser Gegend weiter nach Westen verschoben. Der Markt lag an der Grenze des Eigentums des Kastellans und des Archidiakons, er konnte also von den Einwohner der beiden Siedlungen besucht werden. Unlängst durchgeführte archäologische

${ }^{29}$ R. Szczygieł, H. Gmiterek, P. Dymmel, Lublin. Dzieje miasta, t. 1: Od VI do końca XVIII wieku, Lublin 2008, S. 24-34; R. Szczygieł, Wokół lokacji Lublina na prawie niemieckim, [in:] Hereditas praeteriti. Additamenta archaeologica et historica dedicata Joanni Gurba Octogesimo Anno Nascendi, red. H. Taras, A. Zakościelna, Lublin 2009, S. 505-506.

${ }^{30}$ R. Szczygieł, Kiedy Lublin otrzymat pierwszy przywilej lokacyjny..., S. 286. 
Untersuchungen bewiesen, dass der ganze Altstädtische Hügel befestigt war. Umgeben war er von einem Schutzwall, auf dem sich eine Holzpalisade mit zwei Toren befand. Das eine führte zur Burg und das andere lag am südlichen Rand, vermutlich an einer anderen Stelle als das heutige Krakauer Tor.

Lublin war also in jener Zeit eine protourbane Siedlung, in der das herzogliche Recht galt. Hier befand sich das Zentrum der Macht, ein Zentrum der Kirchenverwaltung. Die Siedlung war auch ein wirtschaftliches Zentrum. Sie lag am wichtigen Handelsweg, der von Kiew über Wolodymyr und Chełm, und ferner über Wąwolnica und Kazimierz zur Weichsel führte. Am linken Ufer des Flusses verzweigte er sich. Der eine Weg führte nach Westen nach Schlesien, der andere nach Norden an die Ostsee. In der zweiten Hälfte des 13. Jhs. wurde Lublin durch die Überfälle der Litauer und der Jazwinger heimgesucht. Die größten erfolgten in den Jahren 1255, 1273, 1278, 1282 und 1285. Der Überfall von 1273 hing mit der Revolte der kleinpolnischen Oligarchie gegen Boleslaw den Schamhaften zusammen. Im Zuge dieser Ereignisse wurde das Lubliner Land durch die Truppen des litauischen Fürsten Trojden verwüstet. Sonst sind noch zwei Überfälle der Mongolen in den Jahren 1259 und 1287 und zahlreiche russinische Überfälle in den Jahren 1265-1266, 1280 und 1288 zu erwähnen. Hinter ihnen verbarg sich das Streben der galizisch-wolhynischen Fürsten nach der Eroberung Lublins und der Lubliner Kastellanei. Das gelang Georg I. Lwowicz im Jahr 1289 bzw. 1290 und bis ca. 1302 stand die Stadt unter russinischer Herrschaft. K. Myśliński stellte die These auf, dass dies mit Billigung von Herzog Władysław Ellenlang geschah ${ }^{31}$.

Nach einer gescheiterten Expedition dieses Fürsten gemeinsam mit Russinen gegen Sandomierz im Jahr 1302 besetzte die Ritterschaft dieser Provinz Lublin, das in den Quellen „Lublinum novum“ genannt wurde. Diese Bezeichnung spricht, wie es scheint, zusätzlich dafür, dass es hier im 13. Jahrhundert keine Stadtlokation gab. In der urbanistischen Literatur lesen wir nämlich, das die Lokationsstädte damals mit dem Begriff: oppidum, civitas bezeichnet wurden ${ }^{32}$.

1302 geriet Lublin für kurze Zeit unter die Herrschaft des böhmischen Königs Wenzel II., der seit 1300 gleichzeitig König von Polen war. Seine Macht war nicht stabil, insbesondere in Anbetracht der immer stärkeren Tendenzen, die fremde Dynastie durch die einheimische Piasten-Dynastie zu ersetzen, deren Vertreter, Władysław Ellenlang, konsequent danach strebte, die Herrschaft über die polnischen Gebiete zu übernehmen. Neben den wirtschaftlichen Faktoren beeinflusste daher die Situation in Lublin auch der Machtkampf im Land Sandomierz, der zwischen Wenzel II. und Władysław Ellenlang ausgetragen

${ }^{31}$ K. Myśliński, Najstarszy Lublin..., S. 171-183; R. Szczygieł, H. Gmiterek, P. Dymmel, op. cit., S. 18-27.

32 Siehe S. Gawlas, Przełom lokacyjny..., S. 152. 
wurde $^{33}$. Als dieser Letztere 1305 in Kleinpolen zu regieren begann, gehörte Lublin ohne Zweifel zu den Zentren, die ihn unterstützten. Es lag aber abseits, fern von den Gebieten, auf denen sich die für den im Einigungsprozess begriffenen Staat wichtigsten politischen und militärischen Vorgänge abspielten.

Wir wissen nicht, welche Haltung die Lubliner Bürger gegenüber den Vorfällen einnahmen, die mit der Meuterei des Vogtes Albert in Krakau zusammenhingen. Gewisse Ereignisse aus der späteren Zeit scheinen aber dafür zu sprechen, dass die Rebellen mindestens von einem Teil der Bürgerschaft unterstützt wurden. Ein wichtiges Indiz ist die am 22. Januar 1315 in Sandomierz ausgestellte Urkunde von Herzog Władysław Ellenlang, in der er den Thorner Kaufleuten verbietet, die Stadt an der Bystrzyca zu besuchen, was für Lublin sehr ungünstig war. Nach K. Myśliński wollte der Herzog dadurch verhindern, dass diese Kaufleute durch Masowien reisen, was damals gefährlich war ${ }^{34}$. Jacek Chachaj äußerte unlängst die Vermutung, dass dies möglicherweise die herzogliche Strafe dafür war, dass die Lubliner Bürgerschaft Sympathien für die Krakauer Rebellen hegte ${ }^{35}$. Das ist eine überaus interessante Schlussfolgerung, denn aus den Untersuchungen von J. Wyrozumski resultiert, dass der Herzog erst im Juni 1315 seine Haltung gegenüber der städtischen Gemeinde Krakau änderte und ihr seine Gunst zu erweisen begann ${ }^{36}$. Es ist auch zu vermerken, dass Lublin im 14. und 15. Jh. sehr enge Kontakte zu Krakau unterhielt. Aus dieser Stadt stammten ja alle Erbvögte.

Als der Herzog das Verbot an die Thorner Kaufleute richtete, leuchtete ihm vielleicht ein, über welches Potenzial Lublin als eine Station auf dem immer wichtiger werdenden, großen Handelsweg verfügte, der vom Schwarzen Meer an die Ostsee und nach Westeuropa führte. Sonst war er damals mit einer antipolnischen Koalition der Kreuzritter mit Böhmen und Brandenburg konfrontiert. Als Gegengewicht stärkte er (unter Nutzung familiäre Bindungen) die Allianz mit Ungarn, dem Fürstentum Halytsch-Wolodymyr und Masowien. Lublin lag quasi am Schnittpunkt der politischen Kontakte mit den Verbündeten, denen sich bald auch Litauen anschloss ${ }^{37}$.

Die oben beschriebenen Umstände waren die Hauptursache dafür, dass Władysław Ellenlang 1316bzw. Anfang 1317 denEntschluss fasste, das protourbane Zentrum Lublin nach dem Modell einer Lokationsstadt nach deutschem Recht umzubauen. Der Urheber dieser Investition war der Herzog selbst. So war es in

${ }^{33}$ K. Myśliński, Najstarszy Lublin ..., S. 182-183.

${ }^{34}$ Idem, Lublin w życiu gospodarczym i politycznym Polski przedrozbiorowej, [in:] Lublin 1317-1967, S. 19.

35 J. Chachaj, Lublin - miasto Rychezy? Lubelskie szkice historyczne XI-XIV wieku, Lublin 2014, S 188-190.

36 J. Wyrozumski, Dzieje Krakowa, t. 1, Kraków 1992, S. 217. Siehe J. Rajman, Kraków, zespół osadniczy, proces lokacji, mieszczanie do roku 1333, Kraków 2004, S. 117.

37 R. Szczygieł, H. Gmiterek, P. Dymmel, op. cit., S. 28. 
jener Zeit bei der Modernisierung der monarchischen Städte üblich. Zum Lokator der Stadt wählte der Herzog einen Mitarbeiter, der das Funktionieren einer Stadt neuen Typs gut kannte: den Krakauer und Sandomierzer Statthalter Maciej, einen Bürger von Krakau, der gleichzeitig Erbvogt von Opatowiec war, das zu den Gütern des Benediktinerklosters in Tyniec gehörte. Jerzy Rajman vermutet, dass er ebenfalls Vogt vom nahe gelegenen Połaniec war ${ }^{38}$.

Der Lokationsprozess einer jeden Stadt setzte sich aus zwei Stadien zusammen: aus der rechtlichen und aus der räumlichen Lokation. Bestandteil der ersten war die Bekanntmachung des Lokationsprivilegs des Monarchen. Dieser nutzte die Vorrechte des Lokationsregales und bestimmte den neuen Status der Siedlung. Die räumliche Lokation umfasste Vermessungs-, Bau- und organisatorische Arbeiten und bestand meist aus fünf Etappen. Die erste, eine Voretappe, betraf die Zeit der Vorbereitungen der städtischen Investition. Der Stifter, in diesem Fall Herzog Władysław, bestimmte selbst oder in Zusammenarbeit mit dem Lokator Maciej die Bedingungen, die die Realisierung der geplanten Unternehmung begünstigen sollten. Darauf folgte die konzeptionelle und Planungsetappe. Entworfen wurde dabei der Stadtplan, der später die Grundlage der Einteilung des städtischen Raumes bildete. In der dritten Etappe erfolgte die Ausmessung des Geländes für die geschlossene Bebauung der Stadt, die Markierung des Marktplatzes, der Straßen, der Wohngrundstücke und des Verlaufs der Linie von Befestigungen. Die vierte Etappe betraf die Bebauung und die Besiedlung. Die fünfte hing wiederum mit der Übernahme der städtischen Funktionen zusammen. Namentlich handelte es sich um die Organisation eines Wochenmarktes und der Gesamtheit des städtischen Lebens, das nunmehr einen neuen Charakter annahm ${ }^{39}$.

Die rechtliche und die räumliche Lokation unterschieden sich hinsichtlich des zeitlichen Faktors. Die rechtliche Lokation erfolgte einmalig. Ihren Ort und ihr Datum (15.08.1317) kann man genau bestimmen. Die räumliche Lokation war hingegen ein langwieriger und komplizierter Prozess, in dessen Verlauf verschiedene Aspekte und Elemente der Wirklichkeit, die mit den urbanen Prozessen wenig zu tun hatten, eine bedeutende Rolle spielten ${ }^{40}$.

Aus den obigen Erwägungen resultiert, dass das Lokationsprogramm die Umwandlungen des städtischen Raumes auf dem Altstädtischen Hügel umfasste. Es handelte sich um einen neuen Gestaltungsplan des Hügels und eine vollständige Umwandlung der städtischen Bevölkerung. Im Einklang mit dem deutschen Recht sollte sie in zwei Kategorien eingeteilt werden: Die eine bildeten die Bürger

${ }^{38}$ J. Rajman, op. cit., S. 277-278, 344; A. Marzec, Urzędnicy małopolscy $w$ otoczeniu Władysława Eokietka i Kazimierza Wielkiego (1305-1370), Kraków 2006, S. 76, 105, 109, 246.

${ }^{39}$ R. Szczygieł, H. Gmiterek, P. Dymmel, op. cit., S. 32-34.

${ }^{40}$ G. Wróblewska, Rozplanowanie nowożytnych miast $w$ Wielkopolsce od XVI do końca XVIII w., Warszawa 1977, S. 201; H. Samsonowicz, Tendencje rozwoju sieci miejskiej..., S. 342; M. Bogucka, H. Samsonowicz, op. cit., S. 77-85. 
(cives), die auf dem Gebiet der Stadt volle Rechte und Privilegien genossen, und die andere die Einwohner (incolae), die diese Vorrechte nicht besaßen. Geringere Wandlungen erfolgten im Bereich der Funktionen der Stadt, weil Lublin die meisten von ihnen bereits in der früheren Zeit erfüllte.

Das königliche Lokationsprivileg - so ist nämlich diese Urkunde zu nennen war also eine rechtliche Lokation von Lublin. Es verlieh Lublin das Magdeburger Stadtrecht, vermutlich nach dem Vorbild der Stadt Krakau, nach dem sich die Organisation der Stadt Opatowiec richtete, wo der Lokator Maciej das Erbvogtamt bekleidete. Es garantierte den künftigen Bürgern das Recht auf den Besitz und die Nutzung der städtischen Grundstücke, namentlich der Wohngrundstücke, der Ackerfelder, der Gärten und Wiesen, die auf einem Gebiet von 100 fränkischen Hufen (ca. 2.500 ha) ausgemessen wurden, die der Herzog der Stadt Lublin verlieh. Die kollektive Verwaltung des verliehenen Bodens war eine der Grundprämissen der Entstehung einer städtischen Gemeinde. Die Verwaltung erfolgte aber nicht sofort, denn das Gebiet musste zunächst als Ganzes ausgemessen werden. Die bewirtschafteten Flächen werden in der städtischen Historiographie als Nutzflächen bezeichnet ${ }^{41}$.

Nach dem Beschluss des Monarchen galten in der Stadt „keine Rechte und Bräuche, die mit dem erwähnten Magdeburger Stadtrecht nicht übereinstimmten“. Die zu gründende städtische Gemeinde erhielt eine Immunität, die die Grundlage der Gestaltung der Verfassung und der städtischen Selbstverwaltung sein sollte. Nach der Entscheidung des Herzogs waren daher die Stadteinwohner unabhängig von der Macht und der Rechtsprechung der „Wojewoden, Kastellane und jeglicher Richter, durch die [so der Wortlaut des Privilegs] die erwähnten Bürger nicht vorgeladen werden dürfen “42. Das bedeutete die Schaffung eines besonderen Gerichtsbezirks, in dessen Gebiet die Rechtsprechung in den Händen des Erbvogts lag. Er wurde angewiesen, über ,große und kleine“ Sachen nach den Vorschriften des Magdeburger Rechts zu entscheiden. Die Bürger hatten aber die Möglichkeit, beim herzoglichen Gericht Berufung einzulegen.

Sie erhielten ebenfalls Weideland für Rinder (in der Urkunde bezeichnet als „Weide der genannten Stadt in drei Richtungen“, also drei Weideflächen). Dieser Abschnitt des Privilegs veranlasste manche Historiker zu dem Schluss, dass man bereits während der Lokation voraussetzte, eine große Rolle im Leben der Einwohner würde die Viehzucht spielen, was eine Bestätigung wirtschaftlicher Schwäche der organisierten Stadt sein sollte ${ }^{43}$.

Der Herzog gewährte den Lubliner Bürgern 20 Freijahre, in denen auf ihnen

${ }^{41}$ S. Liszewski, Rozwój terytorialny a integracja przestrzeni miasta na przykładzie Lodzi, [in:] Wielkie miasto. Czynniki integrujace i dezintegrujace, red. D. Bieńkowska, Łódź 1995, S. 34.

${ }^{42}$ KdM, t. 2, Nr. 569. Den Text des Privilegs publizierte J. Szymański, op. cit., S. 284-287.

${ }^{43}$ Dzieje Lublina - próba syntezy, red. J. Mazurkiewicz, t. 1, Lublin 1965, S. 51; M. Stankowa, Kancelaria miasta Lublina XIV-XVIII w., Warszawa 1968, S. 20-21; J. Szymański, op. cit., S. 275. 
keine Pflichten und Steuern lasteten. Die Länge der Befreiung von den Lasten deutete man ebenfalls als Zeichen schwacher Aussichten der Stadt auf eine Entwicklung ${ }^{44}$. Man muss allerdings bemerken, dass man 15 und mehr Freijahre im 14. Jh. in Kleinpolen Zentren gewährte, die neu erbaut bzw. gründlich umgebaut werden sollten ${ }^{45}$. Nachdem Ablauf der Freijahre 1337, sollten die Bürger einen Zins in der Höhe eines Vierdings (12 Groschen) von der Hufe der genutzten Fläche zahlen ${ }^{46}$.

Eine wichtige Formulierung in der Urkunde von 1317 war die unbefristete Befreiung der Lubliner Bürger von den Zollgebühren auf dem ganzen Gebiet des Staates von Władysław Ellenlang. Vermutlich sollte es eine Anregung zur Entwicklung Lublins zu einem überregionalen Handelszentrum sein. Diese Bestimmung hing zweifellos mit der Politik des Herzogs Władysław gegenüber den Städten in seinem Staat zusammen. Die Nutznießer dieser Politik waren Alt und Neu Sandez, Żmigród (dt. Trachenberg) und Lublin ${ }^{47}$.

Den zweiten Teil der Verfügung des hier erörterten Privilegs bildet die Beschreibung des Vermögens der Erbvogtei, die der Lokator Maciej für die Durchführung der Lokation von Lublin erhalten sollte. Das Areal des dem Vogt zuerkannten Bodens: „frei [jede] sechste Hufe unter den städtischen Hufen“. Vor 50 Jahren hat Józef Szymański die Hypothese aufgestellt, dass in der Urkunde nicht von 1/6 der Hufen, sondern vom sechsten Denar des Zinses von einer jeden Hufe gibt. Dies würde jedoch bedeuten, dass es vor der Ausstellung dieses Dokuments diese Regelung noch nicht gab ${ }^{48}$. Gleichzeitig ist es eine Voraussetzung für die Behauptung, dass das Gebiet der Stadt noch nicht ausgemessen und nicht markiert war. Der Vogt erhielt ansonsten 1/3 der Einnahmen von den gerichtlichen Strafen und Einkünfte von Metzgereien, Verkaufsbuden und städtischen Gasthöfen, von den Zünften der Bäcker und der Schuster, von jedem sechsten Tuchladen und vom städtischen Schlachthof. Es war eine in der damaligen Zeit typische Verleihung der Unterhaltsgelder für einen Vogt. Hinzu kam in Lublin das städtische Badehaus, das Vorrecht des Baus von Mühlen an den Flüssen in den Grenzen der Stadt und das ausschließliche Recht auf Fischfang in den Teichen. In Lublin gab es damals zwei Teiche: einer befand sich auf der Bystrzyca östlich und südlich vom Hügel (Großer Teich), der andere auf dem Fluss Czechówka,

${ }^{44}$ K. Myśliński, Lublin w życiu gospodarczym i politycznym ..., S. 20.

${ }^{45}$ Dzieje Lublina ..., S. 51. Siehe A. Berdecka, Lokacje i zagospodarowanie miast królewskich w Małopolsce za Kazimierza Wielkiego (1333-1370), Warszawa 1982, S. 56-57; F. Kiryk, Rozwój urbanizacji Małopolski..., S. 50 (Ciężkowice), 118 (Grybów), 126 (Lipnica), 250 (Tymbark), 285 (Kęty), 303 (Zator).

${ }^{46}$ KdM, t. 2, Nr. 569; J. Szymański, op. cit., S. 86.

${ }^{47}$ Dzieje Lublina ..., S. 51; A. Obara-Pawłowska, Polityka gospodarcza Władysława Lokietka, Lublin 2014, S. 291-300.

48 J. Szymański, op. cit., S. 274. 
dort wo heute die Allee der Gewerkschaft Solidarność verläuft. Aus dem Wortlaut der Urkunde geht fervor, dass alle Anlagen, die mit der Wirtschaft und dem städtischen Leben zusammenhingen, erst gebaut werden sollten ${ }^{49}$.

In der Historiographie von Lublin wird die Ansicht vertreten, dass die Wahl des Statthalters Maciej zum Lokator von Lublin von einer finanziellen Schwäche dieses Zentrums zeugt ${ }^{50}$. Dagegen ist einzuwenden, dass es in den polnischen Gebieten in der Periode der Lokationsbewegung der Städte eine absolute Seltenheit war, dass zum Lokator ein bisheriger Einwohner einer Stadt ernannt wurde. Es war im 13. und 14. Jh. die Regel, dass das neue Zentrum vom Bewohner einer bereits funktionierenden Stadt organisiert wurde. Von dort übernahm er meist die Muster für das zu erbauende Zentrum. Ein solcher Mensch war das von Herzog Władysław Ellenlang zum Lokator von Lublin gewählte Mitglied des Krakauer Patriziats Maciej. In dieser Stadt besaß er zahlreiche Immobilien und führte Geschäfte gemeinsam mit seinem Bruder Piotr. Als Statthalter berief er im Namen des Herrschers die Krakauer Ratsherren (z.B. 1321), besaß die Erbvogteien in Opatowiec und (möglicherweise) in Połaniec und unterstützte den Monarchen beim Umbau des Finanzwesens des vereinigten Staates ${ }^{51}$. Er war also jemand, der die städtischen Gemeinden neuen Typs gut kannte und die Zuständigkeit besaß, die städtische Investition in Lublin durchzuführen. Ihre Realisierung bedurfte nämlich finanzieller Aufwendungen und Maciej war ein wohlhabender Mensch.

Zum Abschluss der Besprechung des Inhalts des Privilegs von 1317 gilt es noch die Frage nach dem Standort dieser Urkunde im Lokationsprozess von Lublin zu beantworten. Es geht namentlich darum, zu bestimmen, ob sie ein Programm für eine erst zu tätigende Investition war oder (wie manche Historiker es haben wollen) bereits im Laufe der Investition bekannt gemacht wurde ${ }^{52}$. Es war in diesem Text mein Bestreben nachzuweisen, dass es der erste Fall war. Die Urkunde vom 15. August 1317 war also ein Programm für den Umbau und der Modernisierung der Stadt. Darauf weist die Analyse ihres Inhalts hin sowie gewisse Analogien mit bekannten Lokationen anderer Städte.

Erst nach der Ausstellung der Urkunde erfolgte die zweite Phase des Lokationsprozesses. Wir wissen aber nicht, ob die Arbeiten an der räumlichen Lokation Lublins und der Organisation der städtischen Gemeinde von dem neuen Vogt direkt geleitet wurden. Vielleicht nutzte er die Dienste von auf die Abwicklung dieser Aufgaben spezialisierten Personen, derer es in jener Zeit in Kleinpolen und

${ }^{49}$ KdM, t. 2, Nr. 569; J. Szymański, op. cit., S. 285-286.

${ }^{50}$ K. Myśliński, Najstarszy Lublin..., S. 184; idem, Lublin $w$ życiu gospodarczym i politycznym..., S. 20.

${ }_{51}$ J. Rajman, op. cit., S. 277-178; A. Marzec, op. cit., S. 105, 109.

${ }_{52}$ M. Stankowa, op. cit., S. 20; F. Kiryk, Z badań nad urbanizacja Lubelszczyzny w dobie jagiellońskiej, „Rocznik Naukowo-Dydaktyczny WSP w Krakowie. Prace Historyczne” 1972, t. 6, S. 142. 
in Schlesien viele gab. Da der Vogt Maciej stark für die Angelegenheiten des Staates engagiert war und als Krakauer Statthalter viele Pflichten hatte, sollten wir eher die zweite Möglichkeit voraussetzen ${ }^{53}$.

Die Voretappe erfolgte bereits in der ersten Hälfte des Jahres 1317. Es ging um die Wahl des Standortes der künftigen Stadt. Man entschied sich für den Altstädtischen Hügel, der sich für die Investition am besten eignete. Der neue räumliche Gestaltungsplan entstand wohl aber erst im Herbst 1317 oder im Jahr 1318. Die Investition erfasste den ganzen Altstädtischen Hügel, dessen Fläche 7 ha betrug. Im Verhältnis zu anderen Lokationsstädten war dieses Gebiet relativ klein. Die Beschaffenheit des Geländes und die damaligen hydrographischen Verhältnisse ließen aber keine andere Möglichkeit zu. Die Täler der Flüsse Bystrzyca, Czechówka und Czerniejówka waren nämlich feucht.

Das Modell der Lokationsstadt erforderte ebenfalls eine Aufhebung der Rechte anderer Besitzer im Stadtgebiet. Diese diente der Vereinheitlichung der Eigentumsstruktur und der von den Städtern geleisteten Zinsen und hing ebenfalls mit der im Entstehen begriffenen Selbstverwaltung der städtischen Gemeinde zusammen. Dieser in den mitteleuropäischen Städten häufigen Erscheinung begegnen wir ebenfalls in Lublin. In Frage kam hier die Siedlung des Archidiakons, der als Ersatz dafür sie das Dorf Dziesiątą bekam. Wenn man annimmt, dass die räumliche Lokation ohne Störungen verlief, ist K. Myśliński zuzustimmen, der die Durchführung dieser Transaktion dem Herzog Władysław Ellenlang zuschreibt, obwohl Jan Długisz behauptet, dass es Kasimir der Große war ${ }^{54}$. Bei der Angabe des Datums 1342 dachte unser großer Historiker vielleicht an die ihm zweifelsohne bekannte Urkunde von König Kasimir dem Großen, der am 25. Januar desselben Jahres die Erbvogtei an Franczko von Mainz, einen Krakauer Bürger, verkaufte ${ }^{55}$. Um die Mitte des 15. Jh. wurde sie von den Erbvögte von Lublin, Janusz Pieczeń und seit 1456 seinem Schwiegersohn Stanisław Morsztyn, eben in Krakau aufbewahrt ${ }^{56}$. Sie war die Grundlage zahlreicher Prozesse um die Lubliner Vogtei, was J. Długosz bestimmt bekannt war ${ }^{57}$. Die Urkunde von Herzog Władysław von 1317 wurde aber bei den Prozessen nicht erwähnt. Zum Tausch der Siedlung des Archidiakons gegen das Dorf Dziesiąta konnte es nicht ohne Einwilligung des Krakauer Bischofs Jan Muskata kommen. Dieser aber, wie es

${ }^{53}$ R. Szczygieł, Wokót lokacji Lublina..., S. 505.

${ }^{54}$ K. Myśliński, Najstarszy Lublin ..., S. 184-185. Vgl. die Bemerkungen von J. Chachaj, op. cit., S. 174-180.

${ }_{55}^{5 d M}$, t. 3, red. F. Piekosiński, Kraków 1887, Nr. 668.

${ }^{56}$ Davon zeugt die Eintragung im Lubliner Grundbuch (Acta terrestria Lublinensia) aus den Jahren 1430-1440, das in Нацыянальны гістарычны apxiy̆ Беларусі in Minsk aufbewahrt wird, k. 29v-30 (vom Februar 1434) Die Information verdanke ich der Frau Prof. Anna Sochacka.

57 Es schrieb davon K. Myśliński, Wójt dziedziczny i rada miejska w Lublinie 1317-1504, Lublin 1962, S. 14. 
Tomasz Pietras erforschte, kehrte in seine Diözese zwischen Februar und August 1317 zurück. Am 10. August hielt er sich in Opatowiec auf, wo der Statthalter Maciej vielleicht mit ihm die Transaktion zu Ende gebracht hat ${ }^{58}$. Fünf Tage später wurde das Lokationsprivileg von Lublin öffentlich bekannt gegeben.

Im Gestaltungsplan der neuen Stadt wurden gewisse Elemente der bisherigen Einteilung des städtischen Raumes beibehalten. Vermutlich führte man auf dem Gelände der ehemaligen Siedlung des Archidiakons und im südwestlichen Teil des Hügels bis zu seiner Spitze, wo später das Krakauer Tor gebaut wurde, Regulierungsarbeiten durch. Die archäologischen Untersuchungen der letzten Jahre bestätigen, dass man im 13. Jh. den ganzen Altstädtischen Hügel bebaute und mit Befestigungen umgab. Sie dokumentieren auch zahlreiche Veränderungen der Einteilung des städtischen Raumes ${ }^{59}$.

Die Raumplanung erfasste ein Netz von Straßen, die in diesem Sektor an die frühere Form ihres Verlaufs anknüpften. Im Zentrum markierte man einen viereckigen, trapezförmigen Markt, deren Fläche ca. 0,4 ha betrug. An seiner nordwestlichen Front verlief die Hauptverkehrsachse der Stadt, die eine Fortsetzung der Grodzka-Straße war. An den Markt schloss sich die bis zum Krakauer Tor verlaufende Krakauer Straße (heute Bramowa-Straße) an. An der östlichen Ecke des Marktes begann eine Straße, die im 16. Jh. Miejska-Straße hieß und zu dem Platz führte, wo die St. Michaelis-Kirche errichtet wurde. Diese Struktur knüpfte an die für die Lokationsstädte typische Schachbrett-Struktur an, wies aber bedeutende Unterschiede auf, die von der Fähigkeit der Landvermesser zeugten, die Planungen an die topographischen Bedingungen anzupassen. Die Bauten im Straßennetz weisen daher unregelmäßige Formen auf und die ausgemessenen Wohngrundstücke haben verschiedene Flächen. Die Folge der Planungen war die Markierung von etwa 120 solcher Grundstücken. Im Jahr 1524 betrug ihre Zahl 135, was eine Folge zahlreicher Regulierungen des städtischen Raumes war, die im 14. und 15. Jahrhundert erfolgten ${ }^{60}$.

Die Häuser baute man vorwiegend aus Holz. Dies gilt sowohl für die Gebäude auf den Wohngrundstücken als auch für öffentliche Bauten (Badehaus, Tore, Heilig-Kreuz-Kapelle, in deren Nachbarschaft man die Dominikaner untergebracht hat). Aus Stein gebaut war lediglich die St. Michaelis-Kirche, deren Entstehung in das erste Viertel des 14. Jh. datiert wird.

Man führte auch Arbeiten an den Befestigungen durch. Ausgebessert und erhöht wurden die mit einer Palisade versehenen Wälle. An den wichtigsten strategischen Stellen der Verteidigungslinie baute man Basteien und Türme.

${ }_{58}$ T. Pietras, ,, Krwawy wilk z pastoratem”. Biskup krakowski Jan zwany Muskata, Warszawa 2001, S. 112.

59 A. Rozwałka, R. Niedźwiadek, M. Stasiak, op. cit., S. 118-163; R. Szczygieł, Wokół lokacji Lublina..., S. 507.

${ }^{60}$ Ibidem, S. 507-508. 
Von diesem letzteren gab es wohl vier. Der „Vogt-Turm“ ist im westlichen Teil der späteren Wehrmauer erhalten geblieben, der andere war das in der Nähe gelegene Krakauer Tor. Im Norden war es das Städtische Tor und ein vierter Tor befand sich im östlichen Teil der Befestigungen ${ }^{61}$.

Herzog Władysław und seiner Umgebung war klar, dass der Erfolg einer Lokation vom Grad der Modernisierung der organisierten Stadt abhängt. Es war also kein Zufall, dass der Herzog am 30. November 1317 ebenfalls in der Nähe von Krakau ein Privileg für seine Mitarbeiter Dzierżko und Ostasz von Bejsce ausstellte, das ihnen erlaubte, 26 zu ihnen gehörende Dörfer nach deutschem Recht zu organisieren. 16 von ihnen lagen in Lubliner Land und 6 in der Nähe von Lublin ${ }^{62}$. Das trug zweifelsohne zur Entwicklung der Marktwirtschaft und zur wirtschaftlichen Aktivierung der ganzen Region bei.

In der Zeit der Herrschaft von Władysław Ellenlang, möglicherweise in derselben Periode, als man die Investitionsarbeiten auf dem Gebiet der Stadt durchführte (Myśliński schrieb, dass dies noch früher erfolgte), unternahm man auch Erd- und Bauarbeiten auf dem Burghügel ${ }^{63}$. Die Burg als Ganzes hat viel gewonnen, ihr Ausbau und ihre Modernisierung wurde aber zur Zeit der Herrschaft dieses Herzogs nicht abgeschlossen. Beides vollendete erst sein Sohn und Nachfolger Kasimir der Große.

Ähnliches gilt für den Lokationsprozess der Stadt. Es fehlen nämlich Informationen über das Engagement des Vogtes Maciej oder seiner Bevollmächtigten. Feststellen lässt sich lediglich, dass sie eine neue Planung des gesamten genutzten Teils im städtischen Raum durchführten, Siedler warben und die städtische Gemeinde organisierten. In erster Linie gilt das für das Schöffengericht, das vermutlich bereits am Anfang sieben vom Erbvogt berufene Schöffen zählte. In seiner Hand lag die ganze Macht. Er war auch Verwalter der Stadt, führte die Aufsicht über ihr inneres Leben und leitete das städtische Gericht. Eine Berufung von seinen Entscheidungen war nur beim herzoglichen und nach 1320 beim königlichen Gericht möglich. Nur vor diesem Gericht konnte man gegen den Vogt klagen, der dann eine Vorladung mit dem herrschaftlichen Stempel erhielt ${ }^{64}$.

Das Funktionieren der städtischen Gemeinde bestätigt die Information von 1338, die im Band I Bullarum Poloniae veröffentlicht wurde, wo „Sygehardus Civis de Lublin“" auftreten ${ }^{65}$. Vermutlich auf dem Gebiet, das in dem Privileg der Stadt zuerkannt wurde, erfolgte später auf Initiative des Lokators Maciej die Lokation von zwei Dörfern: Bronowice und Konopnica. Das erste verdankt

${ }^{61}$ Ibidem, S. 508.

62 A. Obara-Pawłowska, op. cit., S. 198, 295.

${ }^{63}$ K. Myśliński, Najstraszy Lublin..., S. 183.

${ }^{64} \mathrm{KdM}$, t. 2, Nr. 569; J. Szymański, op. cit., S. 286.

${ }^{65}$ Bullarium Poloniae, Vol. 1: (1000-1342), red. I. Sułkowska-Kurasiowa, S. Kuraś, Romae 1982, Nr. 1865. 
wohl seinen Namen einem Dorf bei Krakau, das durch die Bürger dieser Stadt 1274, also 17 Jahre nach der großen Lokation Krakaus, loziert wurde ${ }^{66}$. Für diese These spricht der Umstand, dass die beiden Dörfer 1342 ein Teil des Vermögens des Vogtes waren ${ }^{67}$. Um das Jahr 1330 verschwindet Maciej aus den Quellen. Vertreten ist in ihnen sein Bruder Piotr, der die Immobilien in Krakau verkaufte. Der Lokator von Lublin lebte wohl nicht $\mathrm{mehr}^{68}$. Die Lubliner Vogtei geriet unter unbekannten Umständen in die Hände des Königs Kasimir des Großen. Plausibel ist also nur die Urkunde dieses Herrschers vom 25. Januar 1342, die den Verkauf der Erbvogtei von Lublin an den Krakauer Bürger Franczko von Mainz für 140 Griwna bestätigt ${ }^{69}$. Diese Urkunde brachte man bisher mit den Verwüstungen in Verbindung, die Lublin 1341 von den Tataren erlitt. Zu beachten ist aber, dass es in der Zeit der Herrschaft des letzten Piasten auf dem polnischen Thron ziemlich häufig zum Verkauf der Erbvogteien in den königlichen Städten kam, besonders derer, die ausgebaut bzw. reloziert werden sollten. Nur in der Wojewodschaft Sandomierz galt dies für die Städte Radom und Zawichost ${ }^{70}$.

Die Ereignisse der ersten Monate des Jahres 1341 blieben aber nicht ohne Einfluss auf die königliche Entscheidung. Die Tataren provozierten die Lemberger Expedition des Königs im Jahr 1340 und sein Eingreifen in die Kämpfe um die Gebiete des Fürstentums Halytsch-Wolodymyr. Sie überfielen im Winter die Lubliner Region und kehrten nach gescheiterten Versuchen, die Weichsel zu überqueren, zurück und begannen Lublin zu belagern. Janko von Czarnków schrieb in seiner Chronik, dass die Angreifer die Gegend der Stadt verwüsteten, die Stadt eroberten und zerstörten. Die Eroberung der Burg gelang ihnen aber nicht, obwohl diese ,aus Holz gebaut war" ${ }^{\text {"“71 }}$. Eben nach dieser Belagerung beschloss König Kasimir die Wehrkraft von Lublin zu stärken, da er die strategische Lage der Stadt wohl einsah.

Mit dieser Entscheidung lässt sich der erwähnte Verkaufsvertrag der Vogtei von 1342 in Verbindung setzen. Diese Urkunde unterscheidet sich wesentlich vom Privileg von 1317. Es ist hier die Rede vom Verkauf der Vogtei, nicht von ihrer Verleihung. In der Verfügung der Urkunde wurde auch sehr genau das Vermögen des Vogtes beschrieben.

Der Erwerber erhielt also die Dörfer Bronowice und Konopnica, die hier zum

${ }^{66}$ Encyklopedia Krakowa, Kraków 2000, S. 85-87.

${ }^{67} \mathrm{KdM}$, t. 3, Nr. 668; J. Riabinin, op. cit., Nr. 3.

${ }^{68} \mathrm{~J}$. Wyrozumski, Maciej (XIII/XIV w.) wielkorzadca krakowski i sandomierski, wójt Opatowca i wójt - zasadźca Lublina, [in:] Polski słownik biograficzny, t. 19, Wrocław 1974, S. 7; J. Rajman, op. cit., S. 277.

${ }^{69} \mathrm{KdM}$, t. 3, Nr. 668; J. Riabinin, op. cit., Nr. 3.

${ }^{70}$ F. Kiryk, Urbanizacja Małopolski..., S. 109, 165.

71 W. Michalski, Tradycje historyczne o tatarskim najeździe na Polskę i oblężeniu zamku lubelskiego zima 1340/1341 roku oraz ich miejsce $w$ dawnej popularnej historii Lublina, „Bibliotekarz Lubelski” 2014, R. LVII, S. 49-84. 
ersten Mal in einer Urkunde erscheinen. Franczko von Mainz erhielt außerdem 6 fränkische Hufen Land im städtischen Gebiet und ein freies Grundstück in der Stadt, wo er sein Haus errichten sollte. Er erhielt auch die Erlaubnis, ein städtisches Badehaus zu bauen und das Einkommen daraus für sich zu behalten. Der König hat sich aber das Recht vorenthalten, dieses Badehaus während seiner Aufenthalte in Lublin zu benutzen. Weitere Verleihungen knüpften an den Inhalt der Urkunde von 1317 an, auf die sich der Verkaufsvertrag beruft. Der Vogt erhielt alle Mühlen, bis auf eine, die sich in der Nähe der Burg befand und wo die Bürger das Malz für die Herstellung von Bier mahlen konnten. Sonst erhielt er das Recht auf den Fischfang, auf die Nutzung der Weide und die Gewinnung des Holzes in den Grenzen der Stadt. Der Vogt bekam auch drei Fleischereien, alle Tuchläden, Verkaufsstände für Salz, Brot und Fische sowie die Schusterbuden. Darüber hinaus kam er in den Besitz des städtischen Schlachthofes, den man cutlow nannte. Traditionell sollte er 1/3 der Einnahmen von den gerichtlichen Strafen und 1/6 der Zinseinkünfte erhalten ${ }^{72}$.

Der zweite Teil der Verfügung betraf das Verbot für Wojewoden, Kastellane und Richter, die Lubliner Bürger vorzuladen. Die Bürger waren ausschließlich der Rechtsprechung des Lubliner Erbvogtes unterstellt, der die Urteile nach deutschem Recht fällen sollte. Die Erinnerung daran, dass über die Handlungen des Vogtes lediglich das königliche Gericht richten kann, nicht die Wojewoden und Richter, erfolgte vielleicht angesichts einer solchen Praxis in der Vergangenheit. Insbesondere konnte sie für den Lubliner Kastellan gelten, der in der benachbarten Burg residierte. Man fügte auch hinzu, dass der Vogt der Provinz, der den Namen eines Landvogtes trug, den Vorsitz des städtischen Gerichts lediglich dreimal jährlich innehaben soll. Es waren die sog. Großgerichte, bei denen der Landvogt den Herrscher vertrat ${ }^{73}$.

So wie es im Fall seines Vorgängers war, haben wir leider über die Wirksamkeit des Erbvogtes Franczko von Mainz keine Informationen. Als er sein Amt bekleidete, gab es in Lublin große Bauarbeiten. Wie wir in der Chronik Jankos von Czarnków lesen, war der Hauptinvestor König Kasimir und seine Beamten in der Lubliner Kastellanei. Die Arbeiten führte man auf dem Gebiet der Lokationsstadt durch, die während der tatarischen Belagerung Schäden erlitten hatte. Man baute eine Wehrmauer aus Stein und aus Ziegelsteinen. Sie umgab das städtische Gebiet und hatte eine Länge von über $1.000 \mathrm{~m}$. Mit Rücksicht auf die Optimierung des Verkehrs hat man die beiden Tore, das Krakauer und das Städtische Tor, umgebaut. Nach 1342 wurden die Gebäude des Dominikanerklosters ausgebaut, was vermutlich eine Vollendung der Investition war, die noch von Władysław Ellenlang unternommen wurde ${ }^{74}$.

\footnotetext{
${ }^{72} \mathrm{KdM}$, t. 3, Nr. 668; J. Riabinin, op. cit., Nr. 3.

73 Ibidem.

74 R. Szczygieł, H. Gmiterek, P. Dymmel, op. cit., S. 34-39.
} 
Breit angelegte Bauarbeiten wurden auch auf dem Burghügel durchgeführt. Umgebaut, eigentlich neu errichtet, wurde die Dreifaltigkeitskapelle, die ein Teil der Wehrbefestigungen der Burg wurde. Die bisherigen Erd- und Holzbefestigungen ersetzte man durch eine Mauer. Diese errichtete man im nördlichen Abschnitt, wo auch eine Bastei entstand. Später errichtete man die Mauer ebenfalls in anderen Teilen der Burg. Vielleicht erhielt die Burg bereits damals eine direkte Verbindung mit der Stadt durch eine Holzbrücke, deren Teil eine Hebebrücke am Städtischen Tor war.

Die Bauarbeiten wurden von umfangreichen Erdarbeiten begleitet, die der Stärkung der Mauer und der Planierung der Abhänge der beiden Hügel dienten. Es ist anzunehmen, dass sie seit 1342 bis zum Tode des Königs Kasimir im Jahr 1370 andauerten. Am intensivsten waren sie aber in den ersten 15 Jahren nach der Zerstörung Lublins durch die Tataren ${ }^{75}$.

Es wird heute angenommen, dass die neue Form des städtischen Raumes, wie sie die Straßen und Plätze, die Bebauung der Wohngrundstücke widerspiegelte, von der Unterordnung der zu gründenden Siedlung unter die künftigen Bedürfnisse der städtischen Gesellschaft und die durch das Zentrum zu erfüllenden Funktionen zeugt. Die im Rahmen der räumlichen Lokation in Lublin durchgeführten Arbeiten betrafen, wie bereits festgestellt, eine Neugestaltung der bereits bestehenden und ausgebauten Infrastruktur für neue Bedürfnisse. Vorrangig handelte es sich um die wirtschaftliche und militärische Funktion des städtischen Zentrums.

Lublin blieb ununterbrochen ein Zentrum der Macht, die vom in der Burg residierenden Kastellan vertreten wurde, ein kirchliches Zentrum mit einer Pfarrkirche und dem Sitz des Archidiakons sowie ein Zentrum der Wirtschaft, die nach der Lokation eine schnelle Modernisierung erlebte, sowohl im Bereich des Handwerks als auch des Handelsaustausches. Es ist dabei zu beachten, dass Lublin als europäisches Handelszentrum bereits in der zweiten Hälfte des 13. Jhs. in Erscheinung trat und seine Bedeutung auf diesem Gebiet um die Mitte des 14. Jhs. zugenommen hat ${ }^{76}$. Die sozialen Wandlungen im Zusammenhang mit der Verleihung des Stadtrechtes, die sowohl alte als auch zahlreiche neue Einwohner der Siedlung erfassten, bewirkten, dass die städtische Gemeinschaft (ähnlich wie in anderen europäischen Städten jener Zeit) korporativ wurde.

In der Zeit der Kämpfe um die Gebiete des Fürstentums Halytsch-Wolodymyr stieg auch die politische Bedeutung der Stadt. Hier trafen König Kasimir der Große und sein Neffe, der König von Ungarn Ludwig zusammen, hier fanden 1358 Verhandlungen mit den Litauern statt. Gerade in jenem Jahr erhielt der Müller Mikołaj vom König das Privileg des Baus von zwei Mühlen, was ein Zeichen des

${ }^{75}$ Ibidem, S. 36-37.

${ }^{76}$ K. Myśliński, Najstarszy Lublin ..., S. 177-178; Dzieje Lublina ..., S. 54-55. 
Anstiegs der Zahl der Bewohner der Stadt ist ${ }^{77}$. Schätzungsweise wohnten damals in Lublin etwa 1000 Personen.

Lublin blieb weiterhin eine Grenzstadt und an der Ostgrenze herrschte Unruhe. Die Stadt war ein Ort der Konzentration der Truppen vor den das Grenzgebiet befriedenden Expeditionen, sowohl in der Zeit Kasimirs des Großen als auch seines Nachfolgers Ludwig. In jener Zeit erschien in Lublin der Stadtrat. Er amtierte in dem auf dem Markt erbauten Rathaus, das 1389 erstmals erwähnt wird ${ }^{78}$. Die Lubliner Bürger befassten sich mit Handwerkstätigkeit, hauptsächlich aber mit dem Handel. Die Führung der Geschäfte auf den Gebieten des Großfürstentums Litauen erleichterte das Privileg der Fürsten Jagiełło und Skirgiełło, das am 15. April 1383 in Wilna ausgestellt wurde ${ }^{79}$. Es hing damals allerdings noch nicht mit den Plänen einer Union zusammen.

Der Weg zur Schließung der Union ist allgemein bekannt. Am 14. August 1385 traf die polnische Delegation mit Fürst Jagieło in Krewo zusammen, wo er die bekannte Urkunde mit den Bedingungen ausstellte, nach denen die Union geschlossen werden sollte. Anschließend kam es zur Zusammenkunft in Wołkowysk. Am 11. Januar 1386 hat dort die polnische Abordnung, deren Mitglieder u.a. der Lubliner Starost Włodko von Charbinowice und der Pächter von Kazimierz Krystyn von Ostrów waren, eine Urkunde ausgestellt, die die Annahme der Bedingungen des Fürsten Jagiełło von Krewo bestätigte und feststellte, dass er zum polnischen König und zum Gatten der Königin Jadwiga gewählt wurde. Gleichzeitig erhielten Jagiełło und sein Gefolge einen Geleitbrief, der ihnen ein sicheres Betreten des polnischen Territoriums gewährleistete. Die Gesandten luden den Großfürsten zum Kongress nach Lublin ein, der am 2. Februar stattfinden sollte ${ }^{80}$.

Zur eigentlichen Wahl Jagiełłos zum polnischen König kam es also am 2. Februar 1386 in Lublin. Vielleicht geschah das auf der Burg. Die polnischen Herren und die Ritterschaft akzeptierten ihn einstimmig als König und Herr. Jan Długosz beschrieb das Ereignis folgendermaßen: „Der Litauische Großfürst Jagiełło, der die Absicht hatte, die Regierung im Königreich Polen zu übernehmen und die Königin Jadwiga zu heiraten [...], besuchte zunächst in Begleitung der polnischen Gesandten die Stadt Lublin und hielt sich dort absichtlich mehrere Tage auf, damit die Kunde über seine Ankunft zu den polnischen Herren gelangte. Von Lublin aus begab er sich in schwerfälligem, langesamem Tempo nach Krakau $[\ldots]^{\lceil 81}$.

77 KdM, t. 3, Nr. 722. Über die Verhandlungen mit den Litauern schreibt A. Marzec, op. cit., S. 184, 226, 234, 251.

${ }_{78}$ W.K. Zieliński, Monografia Lublina, Lublin 1878, S. 31.

${ }^{79}$ Katalog dokumentów miasta Lublina 1317-1792, red. M. Trojanowska, Lublin 1996, Nr. 7.

${ }^{80}$ R. Szczygieł, H. Gmiterek, P. Dymmel, op. cit., S. 42-43.

${ }^{81}$ J. Dlugossii Annales seu cronicae incliti Regni Poloniae, liber X, 1370-1405, red. D. Turkowska, M. Kowalczyk, commentarii Z. Perzanowski, Varsoviae 1985, S. 151. 
In diesen wenigen Tagen hatte Jagiełło die Möglichkeit, Lublin kennenzulernen. Er behielt die Stadt in dankbarer Erinnerung und besuchte sie in der Zeit seiner 48-jährigen Herrschaft häufig.

Die Union Polens mit Litauen bewirkte, dass Lublin im vereinigten Staat eine zentrale Rolle zufiel. Es lag im Grenzgebiet dreier wirtschaftlicher und kultureller Zonen (Litauen, die Rus' und Polen), die für ihre Entwicklung den Austausch brauchten. Aufmerksam machte darauf 1930 Leon Koczy, was später in der Literatur häufig wiederholt wurde ${ }^{82}$. Die Wirtschaftsgeschichte folgt der Wirtschaftsgeographie und nennt solche Zentren ,Städte - Tore zur Wirtschaft benachbarter Regionen“. Eine solche Rolle als Tors fiel im 15. und 16. Jh. Lublin zu. Die Einwohner nutzten diese Chance und vergrößerten in den Jahrzehnten nach der Schließung der Union systematisch ihre Beteiligung am großen Handelsaustausch in Mitteleuropa. Eben dieser Handel entschied in den nachfolgenden zwei Jahrhunderten über den Rang des Lubliner Zentrums im städtischen Netz der Monarchie der Jagiellonenmonarchie, beeinflusste den Rhythmus des städtischen Lebens, die von den Einwohnern ausgeübten Berufe und ihren Wohlstand. Diese Bedingungen bildeten eine gute Grundlage für die Entwicklung der städtischen Gemeinde auf ihrem Weg zur Glanzzeit.

\section{LITERATURVERZEICHNIS}

\section{Quellen}

Bullarium Poloniae, Vol. 1: (1000-1342), ed. I. Sułkowska-Kurasiowa, S. Kuraś, Romae 1982.

J. Dhugossii Annales seu cronicae incliti Regni Poloniae, liber X, 1370-1405, red. D. Turkowska, M. Kowalczyk, commentarii Z. Perzanowski, Varsoviae 1985.

Katalog dokumentów miasta Lublina 1317-1792, red. M. Trojanowska, Lublin 1996.

Kodeks dyplomatyczny Małopolski, red. F. Piekosiński, t. 2-3, Kraków 1886-1887.

Lublin w dokumencie 1317-1967, red. F. Cieślak, H. Gawarecki, M. Stankowa, Lublin 1976.

Lustracja województwa lubelskiego 1565, red. A. Wyczański, Wrocław 1959.

Riabinin J., Materiaty do historii miasta Lublina 1317-1792, Lublin 1938.

Szymański J., Dokument lokacyjny Władysława Lokietka dla Lublina z 1317 roku, [in:] Lublin 1317-1967, red. H. Zins, Lublin 1967.

\section{Literatur}

Bartlett R., The Making of Europe. Conquest, Colonization and Cultural Change 950-1350, London 1994. Berdecka A., Lokacje i zagospodarowanie miast królewskich w Matopolsce za Kazimierza Wielkiego (1333-1370), Warszawa 1982.

${ }^{82}$ L. Koczy, Handel Poznania do połowy XVI wieku, Poznań 1930, S. 50; H. Samsonowicz, Handel Lublina na przetomie XV i XVI w., „Przegląd Historyczny” 1968, t. 59, S. 612-626; K. Myśliński, Lublin na dawnych szlakach handlowych, [in:] Lublin w dziejach i kulturze polskiej, red. T. Radzik, A.A. Witusik, Lublin 1997, S. 30-39. 
Bogucka M., Samsonowicz H., Dzieje miast i mieszczaństwa w Polsce przedrozbiorowej, Wrocław 1986.

Braudel F., Civilisation matérielle, économie et capitalisme, XVe - XVIIIe siècle, Vol. I: Les structures du quotidien: le possible et l'impossible, Paris 1979.

Chachaj J., Lublin - miasto Rychezy? Lubelskie szkice historyczne XI-XIV wieku, Lublin 2014.

Dzieje Lublina - próba syntezy, red. J. Mazurkiewicz, t. 1, Lublin 1965.

Encyklopedia Krakowa, Kraków 2000.

Ennen E., Die europäische Stadt des Mittelalters, 3. Aufl., Göttingen 1979.

Froehlichowa Z., Z dziejów organizacji władz miejskich Lublina do końca XVII w., „Pamiętnik Lubelski" 1930, t. 1.

Gawlas S., O ksztalt zjednoczonego królestwa. Niemieckie władztwo terytorialne a geneza społeczno-ustrojowej odrębności Polski, Warszawa 2000.

Gawlas S., Polska Kazimierza Wielkiego a inne monarchie Europy Środkowej - możliwości i granice modernizacji władzy, [in:] Modernizacja struktur władzy w warunkach opóźnienia. Europa Środkowa $i$ Wschodnia na przełomie średniowiecza i czasów wczesnonowożytnych, red. M. Dygo u.a., Warszawa 1999.

Gawlas S., Przełom lokacyjny $w$ dziejach miast środkowoeuropejskich, [in:] Civitas Posnaniensis. Studia z dziejów średniowiecznego Poznania, red. Z. Kurnatowska, T. Jurek, Poznań 2005.

Heers J., La ville au Moyen Âge en Occident. Paysages, pouvoirs et contiflicts, Paris 1990.

Kamińska K., Lokacje miast na prawie magdeburskim na ziemiach polskich do 1370 r., Torun 1990.

Kiryk F., Lokacje miejskie nieudane, translokacje miast i miasta zanikłe w Małopolsce do połowy XVII stulecia, „Kwartalnik Historii Kultury Materialnej” 1990, t. 28.

Kiryk F., Rozwój urbanizacji Małopolski XIII-XVI wieku. Województwo krakowskie (powiaty południowe), Kraków 1985.

Kiryk F., Urbanizacja Małopolski. Województwo sandomierskie XIII-XVI wiek, Kielce 1994.

Kiryk F., $Z$ badań nad urbanizacja Lubelszczyzny $w$ dobie jagiellońskiej, „Rocznik Naukowo-Dydaktyczny WSP w Krakowie. Prace Historyczne" 1972, t. 6.

Koczy L., Handel Poznania do połowy XVI wieku, Poznań 1930.

Kuraś S., Przywileje prawa niemieckiego miast $i$ wsi małopolskich XIV-XV wieku, Wrocław 1971.

Kurtyka J., Odrodzone Królestwo. Monarchia Władystawa Lokietka i Kazimierza Wielkiego wświetle nowych badań, Kraków 2001.

Liszewski S., Rozwój terytorialny a integracja przestrzeni miasta na przykładzie Lodzi, [in:] Wielkie miasto. Czynniki integrujące i dezintegrujące, red. D. Bieńkowska, Łódź 1995.

Małowist M., Wschód a Zachód Europy w XIII-XVI wieku, Warszawa 1975.

Marczewski J.R., Duszpasterska działalność kościoła w średniowiecznym Lublinie, Lublin 2002.

Marzec A., Urzędnicy małopolscy w otoczeniu Władysława Łokietka i Kazimierza Wielkiego (13051370), Kraków 2006.

Mączak A., Samsonowicz H., Z zagadnień genezy rynku europejskiego: strefa baltycka, „Przegląd Historyczny" 1964, t. 55.

Michalczuk S., O początkach Lublina, czyli geneza układu urbanistycznego Starego Miasta, „Biuletyn Historii Sztuki” 1970, nr 2.

Michalski W., Tradycje historyczne o tatarskim najeździe na Polskę i oblężeniu zamku lubelskiego zima 1340/1341 roku oraz ich miejsce $w$ dawnej popularnej historii Lublina, „Bibliotekarz Lubelski" 2014, R. LVII.

Młynarska-Kaletynowa M. Rozwój sieci miejskiej na Śląsku na przełomie XII/XIII $i$ w XIII w., „Kwartalnik Historii Kultury Materialnej” 1980, t. 28.

Morris A.E.J., A History of Urban Form. Belfore the Industrial Revolutions, New York 1994.

Müller W., Data lokacji Lublina, „Roczniki Humanistyczne” 1960, t. 9, z. 4 (Druck - 1961).

Myśliński K., Lublin na dawnych szlakach handlowych, [in:] Lublin w dziejach i kulturze polskiej, red. T. Radzik, A.A. Witusik, Lublin 1997. 
Myśliński K., Lublin w życiu gospodarczym i politycznym Polski przedrozbiorowej, [in:] Lublin 1317-1967, red. H. Zins, Lublin 1967.

Myśliński K., Najstarszy Lublin - proces tworzenia się średniowiecznego miasta, „Rocznik Lubelski" 1966, t. 9 (Druck - 1961), S. 180-181.

Myśliński K., Wójt dziedziczny i rada miejska w Lublinie 1317-1504, Lublin 1962.

Obara-Pawłowska A., Polityka gospodarcza Władysława Łokietka, Lublin 2014.

Pietras T., ,Krwawy wilk z pastoratem”. Biskup krakowski Jan zwany Muskata, Warszawa 2001.

Rajman J., Kraków, zespół osadniczy, proces lokacji, mieszczanie do roku 1333, Kraków 2004.

Rosłanowski T., Z zagadnień lokacji miejskich w Europie Zachodniej i Środkowo-Wschodniej wśredniowieczu, [in:] Studia nad etnogeneza Stowian i kulturą Europy wczesnośredniowiecznej, red. G. Labuda, S. Tabaczyński, t. 2, Wrocław 1988.

Rozwałka A., Niedźwiadek R., Stasiak M., Lublin wczesnośredniowieczny, Warszawa 2006.

Samsonowicz H., Cechy rzemieślnicze w średniowiecznej Polsce. Mity i rzeczywistość, „Przegląd Historyczny" 1984, t. 75.

Samsonowicz H., Handel Lublina na przełomie XV i XVI w., „Przegląd Historyczny” 1968, t. 59.

Samsonowicz H., Miejsce Polski w Europie, Warszawa 1996.

Samsonowicz H., Struktura zawodowa mieszczaństwa w dawnej Polsce, [in:] Historia i archiwistyka. Ksiegga pamiatkowa ku czci profesora Andrzeja Tomczaka, red. J. Dygdała, B. Woszczyński, Torun 1992.

Samsonowicz H., Tendencje rozwoju sieci miejskiej w Polsce późnośredniowiecznej, „Kwartalnik Historii Kultury Materialnej" 1980, t. 28.

Stankowa M., Kancelaria miasta Lublina XIV-XVIII w., Warszawa 1968.

Szczygieł R., Kiedy Lublin otrzymat pierwszy przywilej lokacyjny na prawie niemieckim?, [in:] Cum gratia et amicitia. Studia z dziejów osadnictwa dedykowane Pani Profesor Marcie Młynarskiej-Kaletynowej z okazji 65-lecia działalności naukowej, red. D. Adamska, K. Chrzan, A. Pankiewicz, Wrocław 2017.

Szczygieł R., Wokót lokacji Lublina na prawie niemieckim, [in:] Hereditas praeteriti. Additamenta archaeologi/ca et historica dedicata Joanni Gurba Octogesimo Anno Nascendi, red. H. Taras, A. Zakościelna, Lublin 2009.

Szczygieł R., Gmiterek H., Dymmel P., Lublin. Dzieje miasta, t. 1: Od VI do końca XVIII wieku, Lublin 2008.

Wędzki A., Początki reformy miejskiej w Europie Środkowej do połowy XIII w., Warszawa-Poznań 1974.

Wiesiołowski J., Sieć miejska Wielkopolski w XIII-XVI wieku. Przestrzeń i społeczeństwo, „Kwartalnik Historii Kultury Materialnej” 1980, t. 28.

Wróblewska G., Rozplanowanie nowożytnych miast w Wielkopolsce od XVI do końca XVIII w., Warszawa 1977.

Wyrozumski J., Czy późnośredniowieczny kryzys feudalizmu dotkną Polske, [in:] Homines et societas. Czasy Piastów i Jagiellonów. Studia historyczne ofiarowane A. Gąsiorowskiemu w 65. rocznicę urodzin, red. T. Jasiński, T. Jurek, J.M. Piskorski, Poznań 1997.

Wyrozumski J., Dzieje Krakowa, t. 1, Kraków 1992.

Wyrozumski J., Maciej (XIII/XIV w.) wielkorzadca krakowski i sandomierski, wójt Opatowca in wójt zasadźca Lublina, [in:] Polski Stownik Biograficzny, t. 19, Wrocław 1974.

Wyrozumski J., Rozwój sieci miejskiej w Małopolsce w średniowieczu i u progu czasów nowożytnych, „Kwartalnik Historii Kultury Materialnej” 1980, t. 28.

Zieliński W.K., Monografia Lublina, Lublin 1878.

Zientara B., Przełom w rozwoju miast środkowoeuropejskich w pierwszej połowie XIII w., „Przegląd Historyczny" 1976, t. 67.

Zientara B., Przemiany społeczno-gospodarcze i przestrzenne miast $w$ dobie lokacji, [in:] Miasta doby feudalnej w Europie Środkowo-Wschodniej. Przemiany spoleczne a uktady przestrzenne, red. A. Gieysztor, T. Rosłanowski, Warszawa 1976 


\section{SUMMARY}

At the beginning of the $14^{\text {th }}$ century the German town laws, spread of Lublin region prompted the development of villages and cities. The Lublin was the first city of region which implemented The Law of Magdeburg. The legal ground of this investment, led by Maciej, the Cracow- and of Sandomierz governer and also the first hereditary vogt (advocatus) in town Opatowiec (the Sandomir), was the location privilege the prince of Ladislaus the Elbow-high, issue "under Cracow" on August 15, 1317.

Till then Lublin was a community, composite from several settlements, situated on hills: Castle-Hill, Old Town-Hill, Thursday, Żmigród. The municipal investment was led on the Old Town-Hill about the area 7 ha, where space was arranged as the chessboard-layout, superbly integrated into the shape of this hill. Municipality was also founded, which use Magdeburg municipal law, at the head which became the hereditary vogt Maciej. Citizens received numerous privileges, i.a. the dismissal from taxes in the interest of the prince during 20 years and the freedom from the payment of the customs duty on the states.

The process of implementation of Magdeburg municipal law was continued under the reign of the king of Kazimir the Great. In this time a number of buildings with stone also defense walls were made. Lublin was a then frontier stage-center of the great trade and the base for expeditions of Russia. The role of Lublin quickly grew up after the union Polish-Lithuanian from 1385-1386, when the city was found in the center of the monarchy of Ladislaus Jagiełło. Lublin situated between Poland, Lithuania, and Russia, performing functions as a center of the commercial exchange and a place of meeting of political elites of both states, Polish and Lithuanian. During the $15^{\text {th }}$ century, the city was promoted to the group of the most important cities of the Jagiellonian Monarchy.

Keywords: Lublin; location privilege; municipality; Magdeburg municipal law; implementation of Magdeburg law

\section{STRESZCZENIE}

W początkach XIV stulecia ruch lokacyjny wsi i miast na prawie niemieckim dotarł do ziemi lubelskiej. Pierwszym miastem tego terytorium, które zostało zmodernizowane według modelu lokacyjnego, był Lublin. Podstawę prawną tej inwestycji, prowadzonej przez Macieja, wielkorządcę krakowskiego i sandomierskiego, a zarazem wójta dziedzicznego w mieście Opatowiec (ziemia sandomierska), był przywilej lokacyjny księcia Władysława Łokietka, wystawiony „pod Krakowem” 15 sierpnia 1317 r.

Do tego czasu Lublin był zespołem osadniczym, złożonym z kilku osad zlokalizowanych na wzgórzach: Zamkowym (gród), Staromiejskim (osada protomiejska), Czwartek, Żmigród. Inwestycja miejska była prowadzona na Wzgórzu Staromiejskim o obszarze 7 ha, gdzie przeprowadzono rozplanowanie według układu szachownicowego, znakomicie wkomponowane w kształt tego wzgórza. Powstała też gmina miejska, która miała się rządzić prawem magdeburskim, na czele której stał wójt dziedziczny Maciej. Obywatele miasta otrzymali liczne przywileje, m.in. zwolnienie na 20 lat od podatków na rzecz księcia i wolność od opłaty cła na terenie jego państwa.

Proces lokacyjny trwał także za panowania króla Kazimierza Wielkiego. Wówczas powstały liczne budowle murowane, zbudowano też mury obronne. Lublin był wtedy nadgranicznym ośrodkiem etapowym wielkiego handlu oraz bazą dla wypraw króla na Ruś. Jego rola szybko rosła po unii polsko-litewskiej z lat 1385-1386, gdy znalazł się w centrum monarchii Władysława Jagiełły, między Polską, Litwą a Rusią, pełniąc funkcje centrum wymiany handlowej oraz zjazdów elit politycznych obydwu państw, polskiego i litewskiego. W ciągu XV w. awansował do grupy najważniejszych miast monarchii Jagiellonów.

Słowa kluczowe: Lublin; lokacja; przywilej lokacyjny; gmina miejska; prawo magdeburskie; proces lokacyjny 